\title{
Angiotensin II promotes endometrial cancer cell survival
}

\author{
MAGDALENA NOWAKOWSKA ${ }^{2 *}, Z^{*}$ ZZANNA MATYSIAK-BURZYŃSKA ${ }^{1 *}$, KAROLINA KOWALSKA $^{1}$, \\ ELŻBIETA PŁUCIENNIK ${ }^{2}$, KAMILA DOMIŃSKA ${ }^{1}$ and AGNIESZKA W. PIASTOWSKA-CIESIELSKA ${ }^{1}$
}

\author{
Departments of ${ }^{1}$ Comparative Endocrinology and ${ }^{2}$ Molecular Carcinogenesis, \\ Medical University of Lodz, Lodz 90-752, Poland
}

Received February 4, 2016; Accepted March 17, 2016

DOI: $10.3892 / o r .2016 .4887$

\begin{abstract}
Endometrial cancer (EC) is one of the most common female cancers. One of the key processes involved in EC development is uncontrolled proliferation stimulated by local factors such as angiotensin. The aim of the present study was to evaluate the influence of angiotensin II (Ang II) on human EC cells. Biological assays and gene expression analysis were performed on three cell lines: ISH, MFE-296 and MFE-280. Our results indicated that at the beginning of cancerogenesis Ang II induced abnormal proliferation at lower doses. We also showed that dose-dependent induction of proliferation was connected with changes in the expression of MKI67, CCNDI and CCNE1 genes in well- and poorly differentiated cancer cells. After Ang II treatment, poorly differentiated endometrial cancer cell line acquired a mesenchymal phenotype, which was characterized by induced expression of EMT-related genes (VIM, CD44, SNAII, ZEBI and $Z E B 2$ ). Our study revealed that Ang II influences EC cells in terms of cancer-related processes, and is responsible for increased proliferation, reduction in apoptosis, increased mobility and modulation of adhesion potential. Its effect and effectiveness appear to be highly connected with the differentiation status of the cancerous cells, as Ang II appears to play a crucial role in the early and late stages of malignant transformation.
\end{abstract}

\section{Introduction}

Endometrial cancer (EC) is one of the most common types of cancer in women, and ranks 4th (7.1\%) in incidence among all female cancers. In 2012 in Poland, 5,426 women were

Correspondence to: Professor Agnieszka Wanda PiastowskaCiesielska, Department of Comparative Endocrinology, Faculty of Biomedical Sciences and Postgraduate Training, Medical University of Lodz, Zeligowskiego 7/9, Lodz 90-752, Poland

E-mail: agnieszka.piastowska@umed.lodz.pl

*Contributed equally

Key words: angiotensin II, endometrial cancer, cell cycle, cell survival diagnosed with endometrial cancer. The highest incidence was observed in women between 60 and 64 years. With regard to mortality, endometrial cancer ranks 11 (2.76\%) with 1,162 deaths in 2012. The highest mortality has been observed in women between 70-74 years (1). Most endometrial cancer cases are diagnosed in the early stages and therefore result in favourable clinical outcomes (2). On the other hand, a significant number of patients with early-stage disease develop both localised recurrence and distant metastases (2). The mechanism of development of these tumours remains unclear. One of the postulated key processes in the development of endometrial tumours is uncontrolled proliferation stimulated by physiological local factors (3). Therefore, various biologically active peptides such as angiotensin, affecting cell proliferation, have become a new area of study in endometrial cancer research.

Angiotensin II (Ang II) is the major octapeptide of the renin-angiotensin system (RAS). For many decades Ang II was mainly perceived as a regulator of the cardiovascular system, an important factor in the pathogenesis of hypertension, atherosclerosis, and angiogenesis. Recently, a number of studies have shown that Ang II plays an important role in proliferation, invasiveness and migration of tumour cells, alteration of expression of cancer-related genes, as well as in physiological tissue remodelling. All components of the RAS (angiotensinogen, angiotensin converting enzyme, angiotensin receptors) are expressed in many types of tumours, including endometrial cancer $(2,4)$. Moreover, both angiotensin receptors (AT1 and AT2) are overexpressed in different types of cancers, which confirms the role of local RAS in cancer development and progression (3,5-8).

The aim of the present study was to evaluate the influence of Ang II on human endometrial cancer cells. Biological assays were performed on well- [Ishikawa (ISH)] moderately (MFE-296) and poorly (MFE-280) differentiated human adenocarcinoma cancer cell lines, representing the G1, G2 and G3 stage of EC. Moreover, we examined alterations in the expression of genes related to cancer cell behaviour after Ang II treatment.

\section{Materials and methods}

Cell culture. ISH, MFE-296 and MFE-280 were obtained from the European Collection of Cell Cultures (Sigma-Aldrich, Poznan, Poland) grown in MEM medium 
supplemented with $10 \%$ fetal bovine serum (FBS), $1 \%$ penicillin-streptomycin-neomycin, $1 \%$ HEPES, $1 \%$ sodium pyruvate and $1 \%$ L-glutamine [ISH cell line additionally required 1\% MEM non-essential amino acid (NEAA)]. All cell culture reagents were obtained from Gibco ${ }^{\circledR}$ by Life Technologies $^{\mathrm{TM}}$ (Warsaw, Poland). Human endometrial ISH cells were derived from well-differentiated adenocarcinoma of the endometrium, while the MFE-296 and MFE-280 cells were obtained from a moderately and poorly differentiated human endometrial adenocarcinoma, respectively.

Experimental design. For each subsequent biological assay, cells were seeded and maintained in the same way. Cells were seeded on 6-well plates (MFE-296 and ISH, 2-5x105/well; MFE-280, 4-10x10 $/$ well) in culture medium with the exception of gene expression analysis, where cells were seeded on $100-\mathrm{mm}$ Petri dishes $\left(1.2 \times 10^{6}\right.$ cells/dish). The next day culture medium was replaced by experimental medium containing human Ang II (Sigma-Aldrich) and incubation was continued for $72 \mathrm{~h}$ at $37^{\circ} \mathrm{C}$. The following conditions were used during the experiments: control without Ang II and medium with 0.1, 1 and $10 \mu \mathrm{g} / \mathrm{ml}$ of Ang II. Experimental media were changed every day.

\section{2-(4-Iodophenyl)-3-(4-nitrophenyl)-5-(2,4-}

disulfophenyl)-2H-tetrazolium (WST-1) assay. The effect of Ang II on the proliferative capacity of endometrial cells was quantified using the WST-1 assay. Briefly, endometrial cells were seeded in 96-well plates at $4 \times 10^{3}$ cells/well in growth medium and incubated overnight under standard culture conditions. Following incubation, the growth medium was discarded and replaced with fresh experimental media containing different concentrations of Ang II and control media. WST-1 assay (Roche Diagnostics GmbH, Mannheim, Germany) was carried out according to the manufacturer's protocols as previously described (9). Cell viability was calculated as: Viability $=($ absorbance of experimental wells $) /($ absorbance of control wells).

Apoptosis analysis. Analysis of apoptosis was performed using Muse ${ }^{\circledR}$ Annexin V \& Dead Cell kit on a Muse automated cell analyser (Merck Millipore, Darmstadt, Germany). This test is based on Annexin V binding to phosphatidylserine (PS), which is predominantly located in the inner leaflet of the plasma membrane under physiological conditions, whereas upon initiation of apoptosis PS is translocated to the extracellular membrane leaflet marking cells as targets of phagocytosis. One hundred microliters of cells suspended in culture medium (with FBS) were used for this analysis. This test was performed according to the manufacturer's instructions.

Cell cycle analysis. Cell cycle analysis was performed using a Muse ${ }^{\text {Th }}$ Cell Cycle kit on a Muse automated cell analyser (Merck Millipore). This test is based on nuclear DNA intercalating stain: propidium iodide (PI), that differentiates cells at various stages of the cell cycle based on differential DNA content. After incubation the cells were harvested and suspended in culture medium (with FBS). Cell cycle assay was performed according to the manufacturer's instructions.
Monolayer cell migration assay wound-healing migration assays. Endometrial cancer cells were seeded on 6-well plates

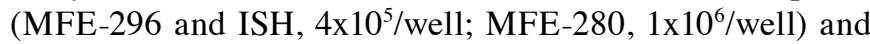
maintained in culture medium until they reached $90 \%$ confluency. Cell monolayers were scraped using a sterile pipette tip forming a cross in the middle of the well. Each well was washed with sterile $1 \mathrm{X}$ PBS to eliminate the unattached cells. Subsequently, the cells were maintained in experimental medium according to the experimental design. Cell cycle blocker, hydroxyurea $(0.5 \mathrm{mM})$ (Sigma-Aldrich), was added to the scratch wound in order to exclude the contribution of cell proliferation to wound closure (10). Images were collected just after the culture medium was replaced with experimental medium and after $72 \mathrm{~h}$ of incubation. Wound area measurements were averaged from the same fields of the same wells, using ImageJ $1.48 \mathrm{v}$ program (http://imagej.nih.gov/ij/ download.html). The influence of Ang II was calculated and presented as the percentage of changes in comparison to the control (100\%).

Adhesion assay. After $72 \mathrm{~h}$ of incubation with Ang II the cells were collected from each well using Trypsin-EDTA $(0.05 \%)$ and counted. The cells were seeded on 24-well plates coated with collagen I, collagen IV, fibronectin or laminin (Corning, BioCoat ${ }^{\mathrm{Tn}}$; Corning Incorporated, Corning, NY, USA); $1 \times 10^{5}$ cells/well from each well from a 6 -well plate were seeded. Plates were incubated for $90 \mathrm{~min}$ at $37^{\circ} \mathrm{C}$, with $5 \% \mathrm{CO}_{2}$. After incubation, each well was washed three times with $200 \mu 1$ sterile $1 \mathrm{X}$ PBS. The remaining cells adhering to the matrix proteins were stained with $0.1 \%$ crystal violet for $10 \mathrm{~min}$. Subsequently, the cells were washed three times with $200 \mu \mathrm{l}$ water. Two hunded microliters of $10 \%$ acetic acid was added to each well to extract the crystal violet from the cells. Dye/solution mixture was transferred into a 96-well plate and measured on an EL808 plate reader (BioTek, Winooski, VT, USA) at $550 \mathrm{~nm}$ wavelength.

Gene expression analysis. RNA was isolated using TRIzol reagent. RNA from triplicates was pooled into one sample. The concentration of RNA was measured using BioDrop DUO spectrophotometer (BioDrop, Cambridge, UK). RNA was transcribed into cDNA using transcription First Strand cDNA Synthesis kit (Roche) according to the manufacturer's instructions. We undertook a two-way approach to RT-qPCR. Firstly, we performed standard RT-qPCR for genes involved in cell cycle and proliferation regulation (CCNDI,CCNEl and MKI67), as well as adhesion ( $\mathrm{CDH1}$ ). The PCR conditions were designed to omit the unspecific products. Each reaction was performed in four replicates. Housekeeping genes (RPS17, $R P L P O$ and $H 3 F 3 A$ ) were used as internal normalization controls and reference RNA (Stratagene, Agilent Technologies, Inc., Santa Clara, CA, USA) as reference samples. The relative gene expression was calculated according to the Roche algorithm. Subsequently, we used TaqMan real-time microarrays-RealTime ready Custom Panel (Roche). For this assay, the reaction mix was prepared using LightCycler ${ }^{\circledR} 480$ Probes Master kit (10 ng of cDNA/well) according to the manufacturer's instructions. The mix was added to RealTime ready Custom Panel with pre-plated genes: $B A D, T G F B, S N A I I$, ZEB2, ZEB1, VIM and CD44. The reaction was carried out 
A

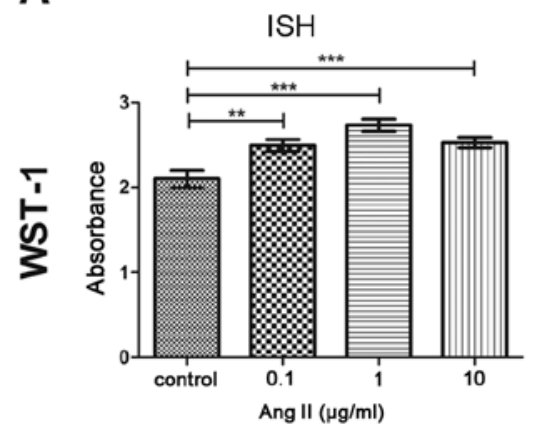

B

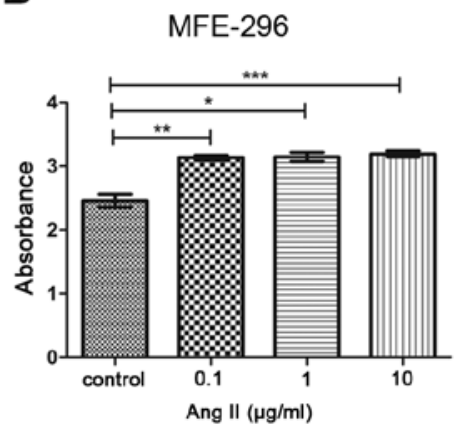

C

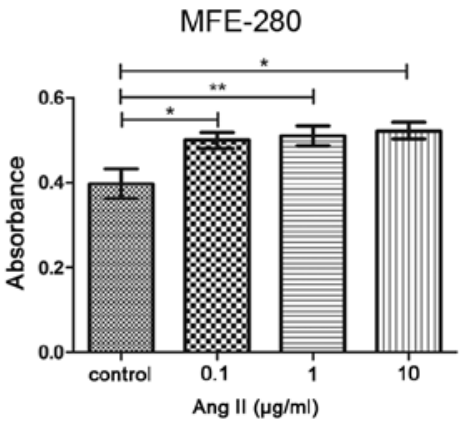

Figure 1. Changes in proliferation potential of endometrial cancer cells after a 72 -h treatment with different doses of Ang II ( $0.1,1,10 \mu \mathrm{g} / \mathrm{ml})$. WST-1 results in (A) ISH, (B) MFE-296 and (C) MFE-280 cell lines. ${ }^{*} \mathrm{p}<0.05,{ }^{* *} \mathrm{p}<0.01$ and ${ }^{* * * *} \mathrm{p}<0.001$, compared to the control.

using Light Cycler ${ }^{\circledR} 480$ II (Roche) according to the manufacturer's instructions. The results from RT-qPCR microarrays are presented as fold change (compared to the control untreated cells). The results from standard RT-qPCR are presented as the mean mRNA expression level.

Statistical analysis. All data are presented as mean $\pm \mathrm{SE}$ and were analysed with GraphPad Prism 5 (GraphPad Software, Inc., La Jolla, USA). Student's t-test was used to compare two groups; the ANOVA test was used to compare differences among multiple groups followed by Bonferroni's multiple comparison tests as applicable. $\mathrm{P}<0.05$ was considered statistically significant.

\section{Results}

Ang II regulates the proliferation of endometrial cancer cells. We first investigated the effect of Ang II on the proliferation of endometrial cancer cells. After a 72-h incubation with Ang II, the proliferative capacity was altered in all tested cell lines in a dose-dependent manner (Fig. 1). The highest increase in proliferation in comparison to the control was observed in the MFE-280 (0.52 \pm 0.02$)$ (Fig. 1C) and MFE-296 cells (3.2 \pm 0.05$)$ (Fig. 1B) following treatment with $10 \mu \mathrm{g} / \mathrm{ml}$ of Ang II. In the case of the ISH cell line, the highest increase was noted in cells treated with $1 \mu \mathrm{g} / \mathrm{ml}$ of Ang II (2.7 \pm 0.07$)$ (Fig. 1A).

Anti-apoptotic activity of Ang II. In order to verify the possible anti-apoptotic activity of Ang II, we performed the Annexin V assay on endometrial cancer cells treated with Ang II for $72 \mathrm{~h}$. In all endometrial adenocarcinoma cell lines Ang II treatment decreased the percentage of apoptotic/dead cells in comparison to the control (untreated cells). In the case of cells derived from poorly and moderately differentiated human endometrial adenocarcinoma, the number of apoptotic/dead cells decreased proportionally to the Ang II dose. In the untreated MFE-280 cells, $12 \%$ of the population was characterized as apoptotic/dead cells, while after incubation with $1 \mu \mathrm{g} / \mathrm{ml}$ of Ang II the percentage of apoptotic cells amounted to $8.7 \%$ and the dose of $10 \mu \mathrm{g} / \mathrm{ml}$ decreased the percentage of apoptotic cells to $8.3 \%$ (Fig. 2C-a). In the control MFE-296 cells, the percentage of apoptotic cells amounted to $11 \%$; whereas after treatment with $1 \mu \mathrm{g} / \mathrm{ml}$ of
Ang II this percentage decreased to $6.4 \%$, and the highest dose of $10 \mu \mathrm{g} / \mathrm{ml}$ resulted in the most pronounced decrease in the percentage of apoptotic cells, 5.3\% (Fig. 2B-a). ISH cells, which represented the well-differentiated adenocarcinoma model, also responded to Ang II treatment by the reduction of apoptotic cell percentage from the control value of 9.5 to 6.4 and $8.2 \%$ after a $72 \mathrm{~h}$-incubation with $1 \mu \mathrm{g} / \mathrm{ml}$ and $10 \mu \mathrm{g} / \mathrm{ml}$ of Ang II, respectively (Fig. 2A-a).

Ang II regulates the cell cycle of endometrial cancer cells. To verify the role of Ang II in the regulation of the cell cycle, we performed flow cytometric analysis of the percentage of cells in different stages of the cell cycle under control conditions and after a 72-h treatment with Ang II (1 or $10 \mu \mathrm{g} / \mathrm{ml})$. In most cases, incubation with Ang II did not cause any significant changes in cell cycle progression in comparison to the control conditions. However, in the MFE-296 cells, Ang II induced transition from the G0/G1 to the G2/M phase (Fig. 3B-b). For this cell line, the percentage of cells in the G0/G1 phase was statistically significantly lower $(75.85 \pm 0.06 \%)$ after treatment with $10 \mu \mathrm{g} / \mathrm{ml}$ of Ang II in comparison to the control $(80.05 \pm 1.1 \%$ ); whereas the percentage of cells in $\mathrm{G} 2 / \mathrm{M}$ phase was significantly higher after treatment with $1 \mu \mathrm{g} / \mathrm{ml}$ Ang II (14.22 $\pm 0.55 \%)$ and $10 \mu \mathrm{g} / \mathrm{ml}$ Ang II (15.6 $\pm 0.32 \%)$ when

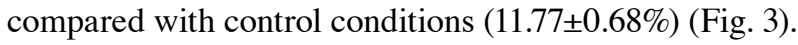

Ang II modulates endometrial cancer cell migration and adhesion. Our previous results as well as data presented by others indicate that Ang II modulates cell mobility in breast cancer cells $(10,11)$. Thus, we performed a monolayer cell migration assay to investigate the influence of Ang II on migration of endometrial cancer cell lines. In the case of moderately and poorly differentiated human endometrial adenocarcinoma cell lines (MFE-296 and MFE-280, respectively), there was a strong tendency towards enhancement of cell migration ability after treatment with $10 \mu \mathrm{g} / \mathrm{ml}$ Ang II (MFE-296, 6 $\pm 2.36 \%$; MFE-280, 3.6 $\pm 0.88 \%$ ) in comparison to the untreated cells (control, 100\% of wound surface) (Fig. 4B and C). In the case of the well-differentiated adenocarcinoma ISH cell line, high migration potential was also observed in cells treated with $1 \mu \mathrm{g} / \mathrm{ml}$ Ang II $(3.6 \pm 6.96 \%)$ in comparison to the control (100\%) (Fig. 4A).

The next step was to investigate the alterations in the ability of endometrial adenocarcinoma cells to adhere to 
A

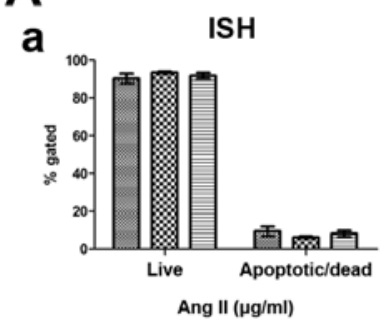

b

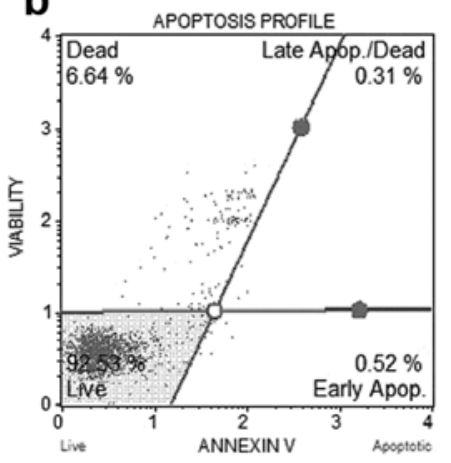

B

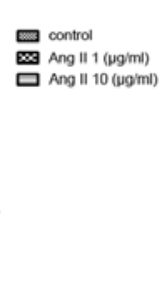

a

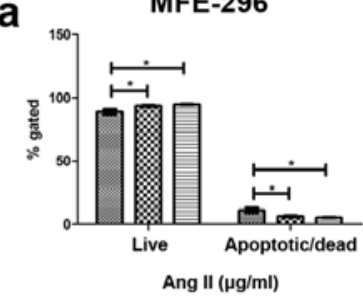

b

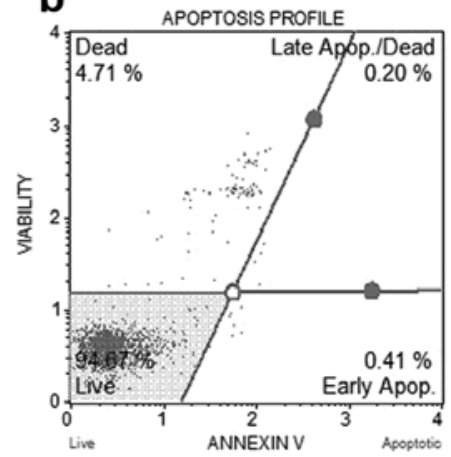

C

a

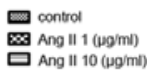

Ang II $1(\mu g / m)$

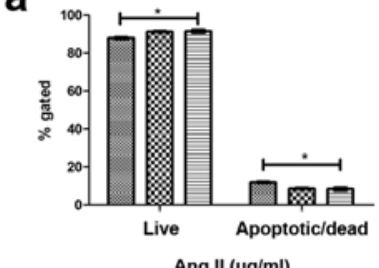

MFE-280

Ang II ( $\mu \mathrm{g} / \mathrm{ml})$

b

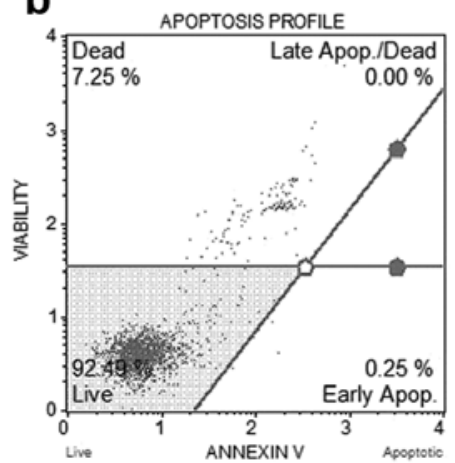

Figure 2. Percentage of gated live and dead cells of three different endometrial andenocarcinoma cell lines: (A-a) ISH, (B-a) MFE-296 and (C-a) MFE-280 following treatment with different doses of Ang II (1 or $10 \mu \mathrm{g} / \mathrm{ml})$ for $72 \mathrm{~h}$. Lower panel - a representative flow cytometry dot plot of apoptosis in (A-b) ISH, (B-b) MFE-296 and (C-b) MFE-280 cell lines following treatment with $10 \mu \mathrm{g} / \mathrm{ml}$ of Ang II. "p $<0.05$ compared to the control.

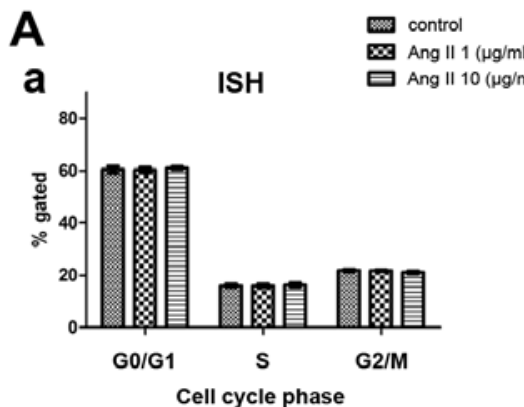

b

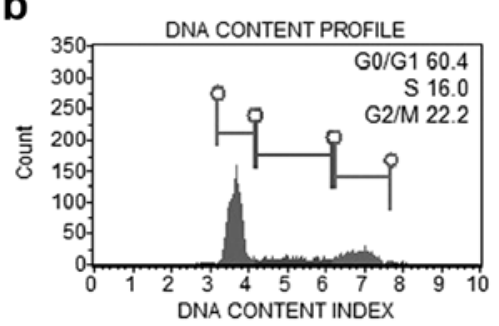

B

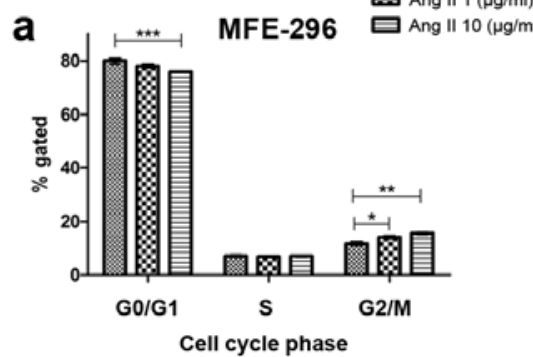

b

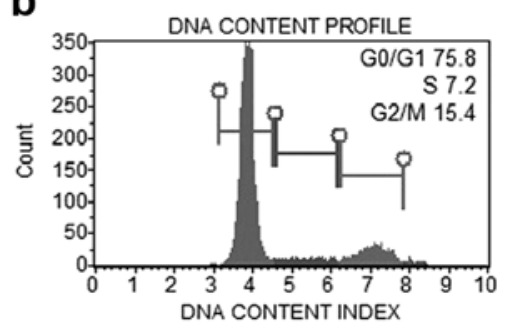

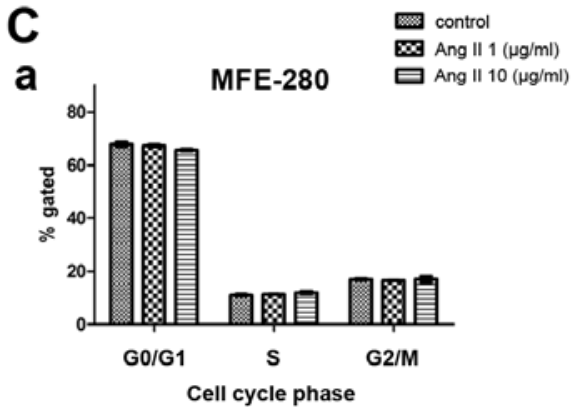

b

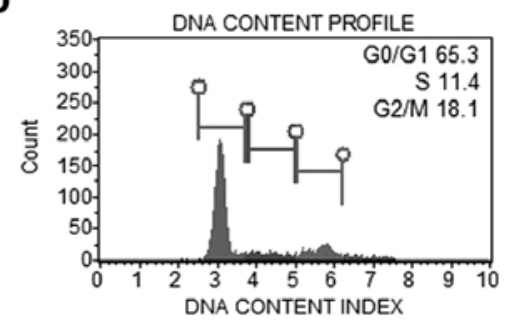

Figure 3. Comparison of the percentage of cells gated in the G0/G1, S and G2/M phases, representing the different cell lines: (A-a) ISH, (B-a) MFE-296 and (C-a) MFE-280 following treatment with 1 or $10 \mu \mathrm{g} / \mathrm{ml}$ of Ang II, or untreated controls. The lower panel presents the DNA content profile in (A-b) ISH, (B-b) MFE-296 and (C-b) MFE-280 cells following treatment with $10 \mu \mathrm{g} / \mathrm{ml}$ Ang II. ${ }^{*} \mathrm{p}<0.05,{ }^{* *} \mathrm{p}<0.01$ and ${ }^{* * * *} \mathrm{p}<0.001$ compared to the control.

various matrix proteins in the presence of Ang II. Poorly differentiated human endometrial adenocarcinoma MFE-280 cells exhibited reduced adhesion ability to matrix proteins after $72 \mathrm{~h}$ of Ang II treatment. After exposure to $10 \mu \mathrm{g} / \mathrm{ml}$ of Ang II a statistically significant reduction in adhesion to fibronectin $(-32.22 \pm 1.73 \%)$, collagen IV $(-28.02 \pm 1.33 \%)$ and collagen I $(-27.4 \pm 3.98 \%)$ was observed in comparison to the control cells (control, 100\%) (Fig. 5). In contrast in the MFE-296 cell line, representing the moderately differentiated model of endometrial adenocarcinoma, no statistically significant changes in adhesion to all tested matrix proteins was noted. In the case of the well-differentiated adenocarcinoma ISH cells, a statistically significant influence of Ang II on cell adhesion was observed. However, the Ang II-induced effect was divergent to that observed for the MFE-280 cell line. The ISH cells treated with $10 \mu \mathrm{g} / \mathrm{ml}$ of Ang II showed enhanced adhesion 


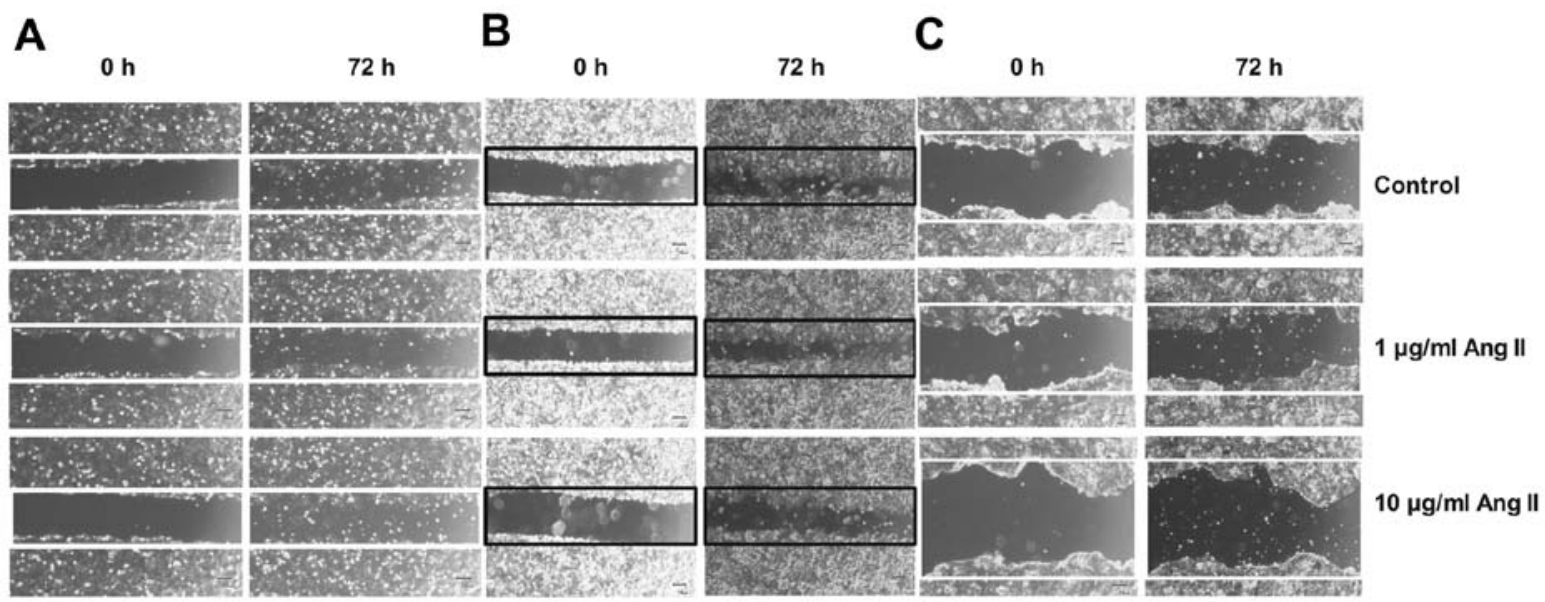

Figure 4. Effects of Ang II treatment on the migration of (A) ISH, (B) MFE-296 and (C) MFE-280 cells. Scratch wound healing assay was performed to examine the effects of Ang II treatment on endometrial cancer cell migration.

A

a

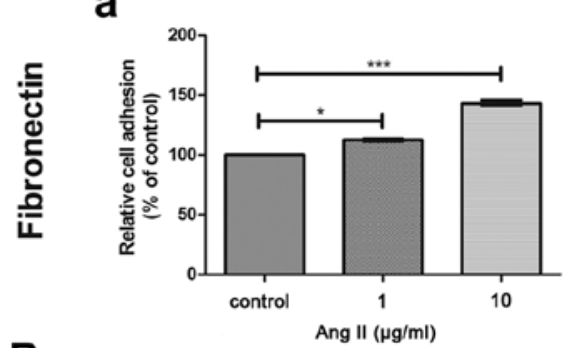

B

a

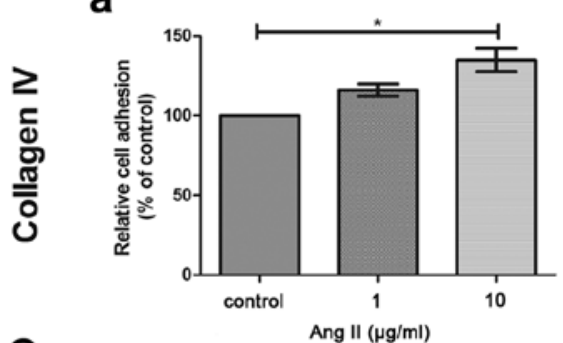

C

a

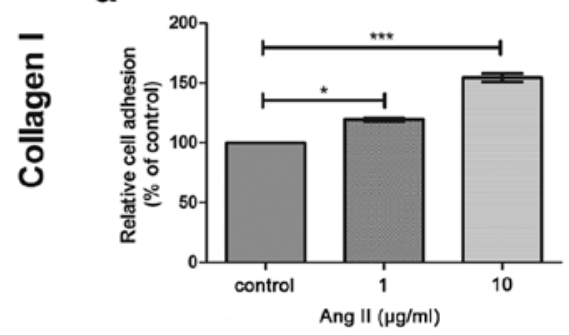

D a

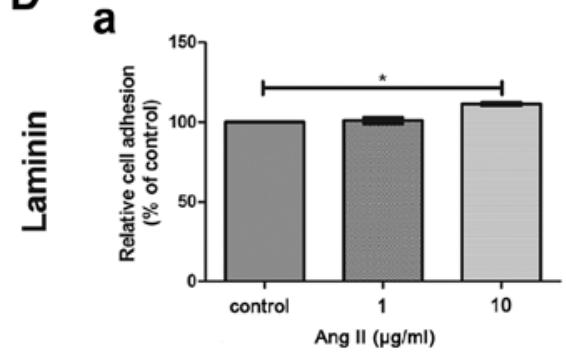

b

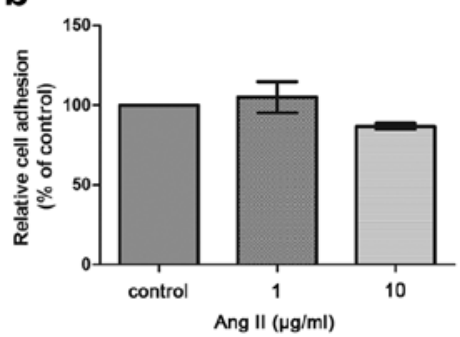

b

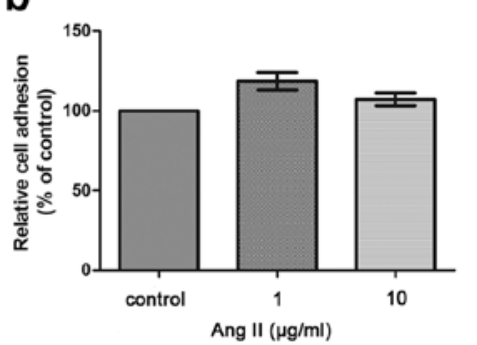

b

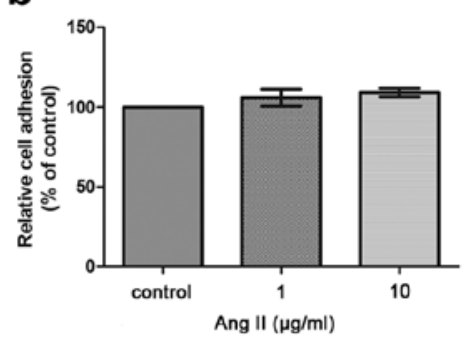

b

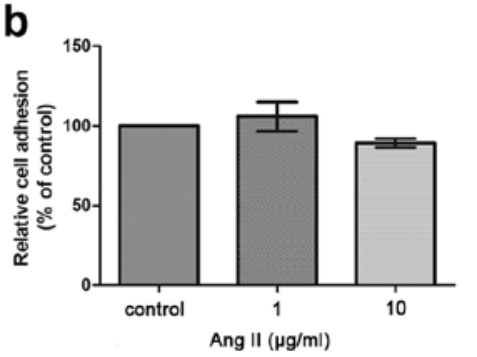

MFE-280

C

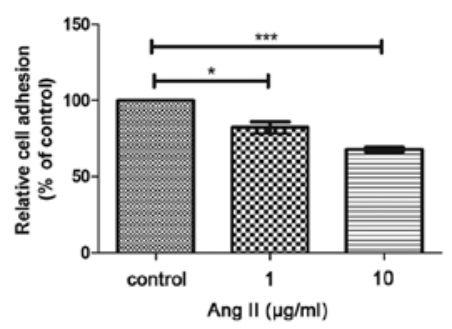

C

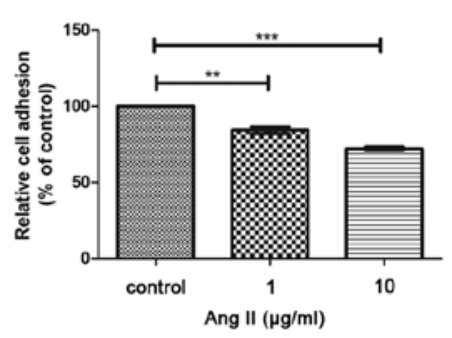

C

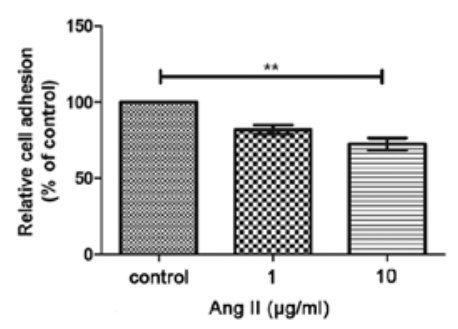

C

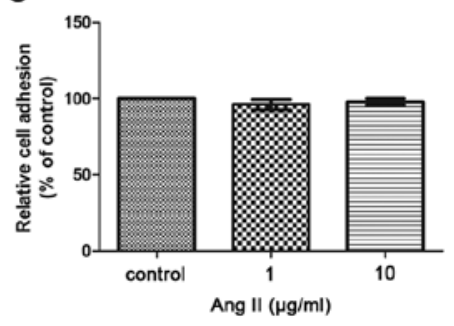

Figure 5. Adhesion to ECM proteins: (A) fibronectin, (B) collagen IV, (C) collagen I, (D) laminin of the endometrial cancer cell lines: (A-a, B-a, C-a and D-a) ISH, (A-b, B-b, C-b, D-b) MFE-296 and (A-c, B-c, C-c, D-c) MFE-280 after treatment with Ang II (1 or $10 \mu \mathrm{g} / \mathrm{ml})$ in comparison to control, untreated cells $(100 \%) .{ }^{*} \mathrm{p}<0.05,{ }^{* *} \mathrm{p}<0.01$ and ${ }^{* * *} \mathrm{p}<0.001$ compared to the control. 
A

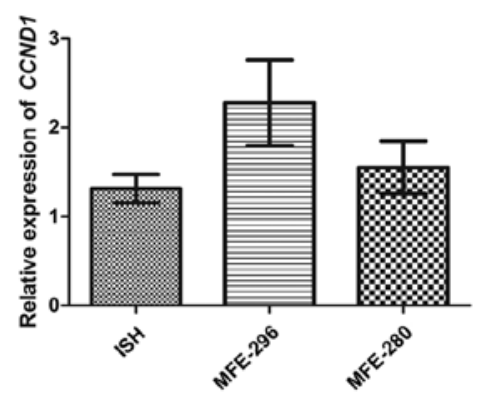

D

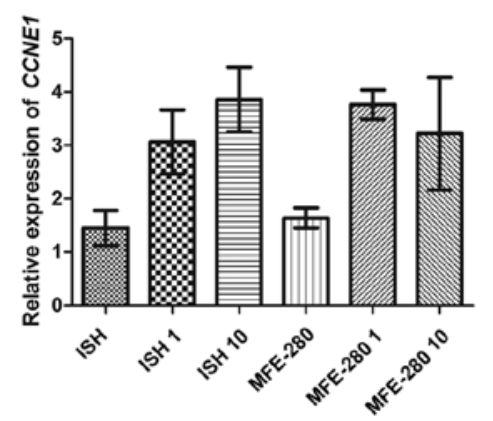

B

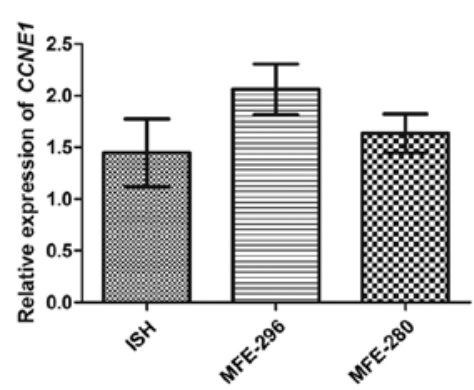

E

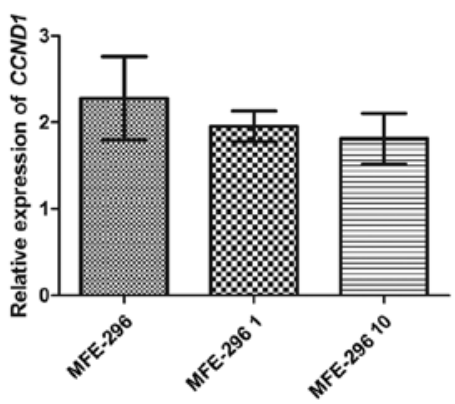

C

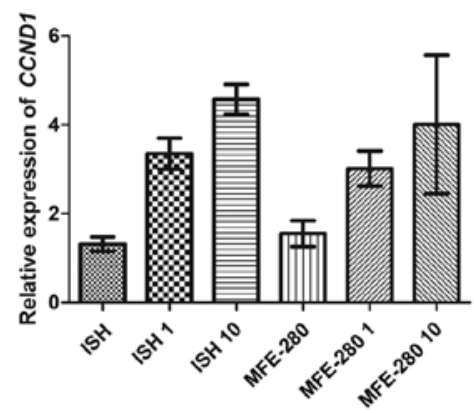

$\mathbf{F}$

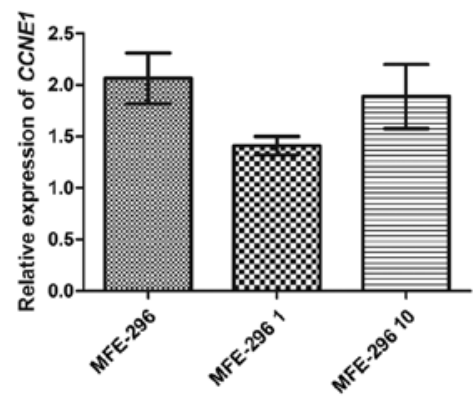

Figure 6. The mRNA expression level changes of genes involved in cell cycle regulation: $C C N D 1, C C N E 1$. (A) The basal level of mRNA of CCND1 in endometrial cancer cell lines: ISH, MFE-296 and MFE-280. (B) The basal level of mRNA of CCNE1 in endometrial cancer cell lines: ISH, MFE-296 and MFE-280. (C) The post-Ang II treatment expression of CCND1 in endometrial cancer cell lines: ISH and MFE-280. (D) The post-Ang II treatment expression of $C C N E 1$ in endometrial cancer cell lines: ISH and MFE-280. (E) The post-Ang II treatment expression of $C C N D 1$ in MFE-296 cells. (F) The post-Ang II treatment expression of $C C N E 1$ in MFE-296 cells. The results are presented as the mean \pm SE mRNA expression level.
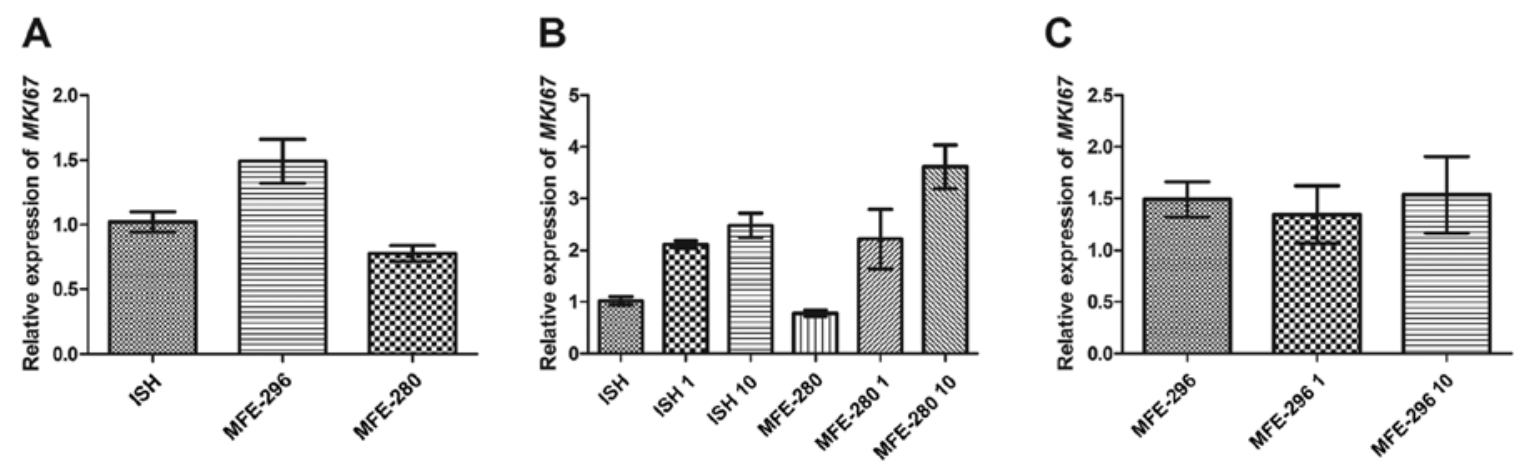

Figure 7. MKI67 mRNA expression level alterations. (A) The basal expression of MKI67 in human endometrial adenocarcinoma ISH, MFE-296 and MFE-280 cells. (B) The post-Ang II treatment expression of MKI67 in ISH and MFE-280. (C) The post-Ang II treatment expression of $M K I 67$ in moderately differentiated human endometrial adenocarcinoma MFE-296 cells. The results are presented as the mean \pm SE mRNA expression level.

to fibronectin $(+43.3 \pm 2.62 \%)$, collagen IV $(+35 \pm 7.24 \%)$, collagen I $(+54.4 \% \pm 3.46)$ and laminin $(+11.3 \% \pm 1.13)$ in comparison to the untreated cells (control, 100\%) (Fig. 5).

Association between Ang II biological activity and changes in gene expression. Next, we verified the association between the observed changes in cellular processes induced by Ang II and the potential changes in the expression of genes involved in the regulation of cell cycle progression, proliferation, motility and programmed cell death. For this analysis we chose the following genes connected with cell cycle regulation: $C C N D 1$ and $C C N E 1$, proliferation: $M K I 67$, apoptosis: $B A D$, cell adhesion: $C D H 1$, motility and induction of epithelial to mesenchymal transition (EMT): TGF $\beta$, SNAII, VIM, ZEBI and ZEB2.

Since we noted that Ang II increased the proliferative activity of the investigated cell lines, we firstly focused on the expression of genes related to cell cycle regulation. The basal level of mRNA expression in the case of both cyclins i.e., $C C N D 1$ and $C C N E 1$ was the lowest in the well-differentiated endometrial adenocarcinoma cell line $(1.3 \pm 0.16$ and $1.4 \pm 0.33$ for CCND1, CCNE1, respectively) (Fig. 6A and B) and higher in the two other cancer cell lines, characterized by lower status of differentiation (Fig. 6A and B). However, when comparing the moderately and poorly differentiated cell lines, we noted that the MFE-296 cells had higher 
A

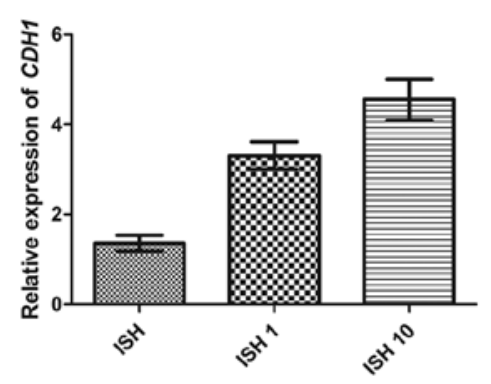

B

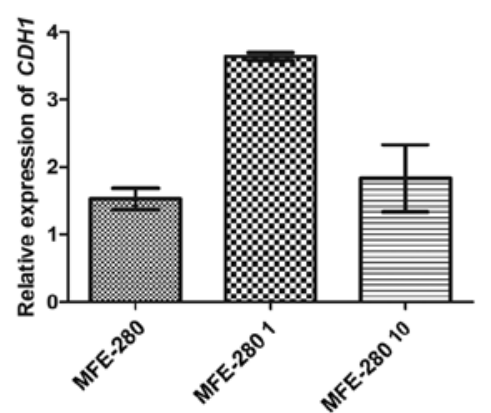

C

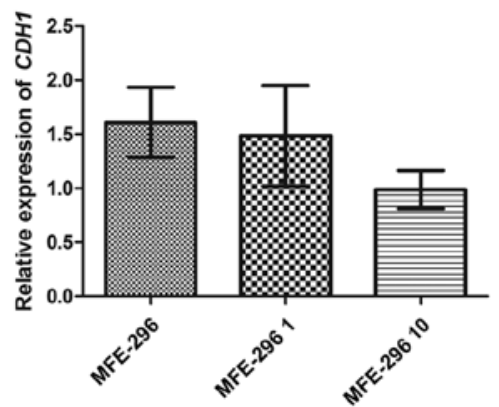

Figure 8. $C D H 1$ mRNA expression level alterations. (A) The post-Ang II treatment expression of $C D H 1$ in ISH cells. (B) The post-Ang II treatment expression of $C D H 1$ in MFE-280 cells. (C) The post-Ang II treatment expression of CDH1 in moderately differentiated human endometrial adenocarcinoma MFE-296 cells. The results are presented as mean mRNA $( \pm \mathrm{SE})$ expression level.

basal mRNA expression of both cyclins than the MFE-280 cells $(2.3 \pm 0.48$ and $2.1 \pm 0.24$ for CCND1 and CCNE1 in MFE-296, respectively vs. $1.6 \pm 0.3 / \pm 0.19$ for both cyclins in MFE-280) (Fig. 6A and B). Furthermore, Ang II increased the expression of both cyclins in a dose-dependent manner only in the well- and poorly differentiated cell lines. The post-Ang II treatment expression of $C C N D 1$ in these cell lines was as follows: $3.4 \pm 0.35$ and $3.0 \pm 0.4$ for ISH and MFE-280 cells, respectively, treated with $1 \mu \mathrm{g} / \mathrm{ml}$ of Ang II, and $4.6 \pm 0.33$ and $4.0 \pm 1.6$ for ISH and MFE-280 cell lines incubated with $10 \mu \mathrm{g} / \mathrm{ml}$ of Ang II (Fig. 6C). The mRNA level of $C C N E 1$ was $3.1 \pm 0.6$ and $3.8 \pm 0.27$ for ISH and MFE-280 cells, respectively, after treatment with $1 \mu \mathrm{g} / \mathrm{ml}$ of

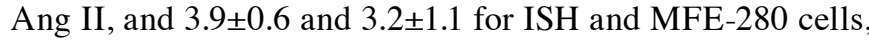
respectively, treated with $10 \mu \mathrm{g} / \mathrm{ml}$ of Ang II (Fig. 6D).

In the case of moderately differentiated MFE-296 cells Ang II caused downregulation of mRNA expression of both cyclins in a dose-dependent manner. The values of CCNDI expression were $2.0 \pm 0.18$ and $1.8 \pm 0.29$, respectively for $1 \mu \mathrm{g} / \mathrm{ml}$ and $10 \mu \mathrm{g} / \mathrm{ml}$ of Ang II (Fig. 6E). A similar tendency was observed in the case of $C C N E 1$, although a slight increase in mRNA expression was higher after the $10 \mu \mathrm{g} / \mathrm{ml}$ Ang II dose than in the presence of $1 \mu \mathrm{g} / \mathrm{ml}(1.9 \pm 0.31$ and $1.4 \pm 0.09$, respectively) (Fig. 6F). This result is quite surprising as the BrdU and WST assays showed increased values after Ang II treatment; however, the proliferation potential was not only regulated by cyclins but also by the main proliferation marker i.e., MKI67.

The basal expression of MKI67 was the highest in the moderately differentiated human endometrial adenocarcinoma MFE-296 cells $(1.5 \pm 0.17)$ and the lowest in the poorly differentiated MFE-280 cell line $(0.78 \pm 0.06)$ (Fig. 7A). However, in the case of well- and poorly differentiated cancer cells, the MKI67 mRNA expression was upregulated by Ang II in a dose-dependent manner and reached values of $2.1 \pm 0.071$ and $2.2 \pm 0.58$, respectively for the ISH and MFE-280 cells treated with $1 \mu \mathrm{g} / \mathrm{ml}$ of Ang II and 2.5 \pm 0.24 and 3.6 \pm 0.42 , respectively for $10 \mu \mathrm{g} / \mathrm{ml}$ of Ang II (Fig. 7B). In the moderately differentiated MFE-296 cells, the changes in MKI67 expression were similar to those observed in the case of cyclin E1 (CCNE1). MKI67 expression was higher after incubation with $10 \mu \mathrm{g} / \mathrm{ml}$ of Ang II than after treatment with the $1 \mu \mathrm{g} / \mathrm{ml}$ dose $(1.5 \pm 0.37$ and 1.3 \pm 0.28 , respectively) (Fig. 7C). The observed changes in expression of proliferation-related genes appear to be consistent with the results of the biological assays, but it is worth noting that the most pronounced effect of Ang II treatment was observed for cancer cell lines showing opposite status of differentiation, i.e., well- and poorly differentiated cell lines: ISH and MFE-280, respectively. This may suggest that Ang II exerts the highest stimulatory actions in cells at the beginning and in the last steps of cancer transformation.

As all treated cell lines responded to Ang II in terms of reduced apoptosis, increased motility and adhesion in a dose-dependent manner, we also evaluated the changes in expression of genes connected with these cellular processes.

First of all, we noted a slight reduction in the expression of proapoptotic gene $B A D$ after treatment with Ang II, and this change was dose-dependent (data not shown). In all investigated cell lines, the highest decrease in $B A D$ expression was observed for $10 \mu \mathrm{g} / \mathrm{ml}$ of Ang II, even though in the biological assays the best results for ISH cells were obtained for lower Ang II dose. Nevertheless, the changes in $B A D$ expression may partially explain the observed reduction in apoptosis obtained in all experimental conditions.

The changes in motility and adhesion induced by Ang II were also reflected by the changes in expression of genes associated with these processes. First of all, we noted that the relative expression of the main epithelial marker $C D H 1$ varied among the investigated cell lines. In well differentiated ISH cells, the basic $C D H 1$ expression level in control cells was 1.4 and increased after Ang II treatment in a dose-dependent manner, i.e., 3.3 for $1 \mu \mathrm{g} / \mathrm{ml}$ and 4.6 for $10 \mu \mathrm{g} / \mathrm{ml}$ of Ang II (Fig. 8A). In contrast, in the poorly differentiated MFE-280 cells we observed a higher increase in $\mathrm{CDH} 1$ relative expression (from the basic level of 1.5 to 3.6) after incubation with $1 \mu \mathrm{g} / \mathrm{ml}$ of Ang II, but after treatment with the dose of $10 \mu \mathrm{g} / \mathrm{ml}$ the level changed significantly ( $C D H 1$ expression level of 1.8) (Fig. 8B). In the moderately differentiated cell line MFE-296, both Ang II doses caused downregulation of $\mathrm{CDH} 1$ expression (basic level 1.6, 1.5 after $1 \mu \mathrm{g} / \mathrm{ml}$ of Ang II and 1.0 after $10 \mu \mathrm{g} / \mathrm{ml}$ of Ang II) (Fig. 8C).

Moreover, we also observed contradictory effects of Ang II treatment on expression of genes connected with the EMT process in two cell lines representing two opposite phenotypes: well- and poorly differentiated (data not shown). Taq-Man real time microarrays revealed that in the ISH cell 
line there was a slight reduction in $T G F \beta$ expression after Ang II treatment. The same situation was observed for SNAII and $Z E B 2$ genes, whose downregulation was stronger after incubation with $10 \mu \mathrm{g} / \mathrm{ml}$ of Ang II (1.2-fold decrease and no detected expression for SNAII and ZEB2, respectively) (data not shown). On the other hand, there was no change in expression of the main mesenchymal marker i.e., VIM, and a 1.3-fold decrease in the level of CD44 mRNA, which is also a known EMT-related mesenchymal marker. In contrast, in the poorly differentiated MFE-280 cells, we observed adverse changes in gene expression to those seen in the ISH cell line. We noted a dose-dependent upregulation of $T G F \beta$ after Ang II treatment. The higher expression was observed for the $10 \mu \mathrm{g} / \mathrm{ml}$ Ang II dose (a 2.3-fold change increase in comparison to the control; a 2-fold increase for the lower experimental dose). Moreover, Ang II at a dose of $10 \mu \mathrm{g} / \mathrm{ml}$ also elevated the expression of other EMT markers, i.e., a 1.3-fold change for SNAII, a 1.1-fold increase for $Z E B 1$, and induction of expression for ZEB2. VIM and $C D 44$ expression was also higher than in the control samples (a 1.3 - and 1.1-fold increase for VIM and CD44, respectively). The moderately differentiated MFE-296 cells showed decreased expression of TGF $\beta$, SNAII, VIM, ZEB1 and $Z E B 2$ (fold change of -1.1, -1.6, -1.2, -1.7, -1.1 for listed genes, respectively) also after treatment with $10 \mu \mathrm{g} / \mathrm{ml}$; whereas the expression of CD44 was not influenced by Ang II treatment.

\section{Discussion}

Previous studies have shown that the local renin-angiotensin system (RAS) has higher activity in various malignant tumour tissues. Moreover, our previous results and data in other studies confirmed that Ang II promotes tumour cell proliferation, migration, and has anti-apoptotic potential $(4,5,9,10,12,13)$. In terms of endometrial cancer, our research demonstrated a correlation between the expression of angiotensin and its receptors and the clinicopathological characteristics of primary endometrial adenocarcinoma (2).

In the present in vitro study on three endometrial adenocarcinoma cell lines representing three stages of endometrial cancer, we performed various biological assays in order to further investigate the specific effects of Ang II on tumour cell behaviour. Firstly, we demonstrated that Ang II influenced the proliferation of well- (ISH), moderately (MFE-296) and poorly differentiated (MFE-280) human endometrial adenocarcinoma cell lines. This response to Ang II was dose-dependent and was previously observed in other cancer models $(4,9,13,14)$. Thus, we confirmed that Ang II promotes cell proliferation also in endometrial cancer. Additionally, in this study we noted that the cellular response to Ang II may be associated with cancer cell differentiation status. In the case of moderately and poorly differentiated cells, the most pronounced response was observed in the dose of $10 \mu \mathrm{g} / \mathrm{ml}$ of Ang II; whereas the well-differentiated ISH cancer cell line showed a significant response in the presence of the lower dose of Ang II $(1 \mu \mathrm{g} /$ $\mathrm{ml})$. This may indicate that at the beginning of cancer cell transformation Ang II may induce abnormal proliferation at lower doses than at the later stages, when the cancer cells have more genomic, transcriptomic and proteomic changes and loose the differentiated phenotype. This hypothesis is also based on the results of real-time PCR analysis, which showed that the dose-dependent augmentation of cell proliferation was connected with increased MKI67, CCNDI and CCNE1 expression in the well- and poorly differentiated cancer cells.

All in all, our present observations, as well as results from previous studies conducted on EC tumour samples, indicate a specific link between angiotensin effectiveness and cell differentiation status (2). Our observations are consistent with data presented by Shan et al, showing that Ang II is capable of promoting endometrial epithelium cell proliferation (6). Similar results on the effect of Ang II on cell proliferation and survival were obtained for breast cancer and prostate cancer $(12,13)$. Moreover, in pancreatic cancer cells, blockage of Ang II type 1 receptor resulted in growth suppression (15). A study by Kinoshita et al (16) also demonstrated that Ang II stimulated gastric cancer cell proliferation (the AT1 receptorpositive OCUM2MD3 cell line) and this proliferative effect of Ang II was mediated by the AT1 receptor.

Next we investigated the influence of Ang II on inhibition of programmed cell death (PCD) - apoptosis. Apoptosis is an evolutionarily conserved process that plays an important role in tissue homeostasis (17). Nevertheless, in some conditions, such as cancer, cells lose their ability to undergo induced PCD leading to uncontrolled proliferation (17). Recent studies have shown that excessive proliferation is connected with inhibition of apoptosis. Herein, we showed that the percentage of apoptotic/dead cells decreased after treatment with Ang II in comparison to the untreated cells. In the case of moderately and poorly differentiated human endometrial adenocarcinoma cells, the smallest percentage of apoptotic/dead cells was noted after treatment with $10 \mu \mathrm{g} / \mathrm{ml}$ dose of Ang II; whereas, in the well-differentiated endometrial adenocarcinoma ISH cell line this percentage was decreased after incubation with $1 \mu \mathrm{g} / \mathrm{ml}$ of Ang II. The observed dose-dependent influence of Ang II on apoptosis further confirms our hypothesis on the connection between Ang II and the differentiation status of endometrial cancer cells. Our results are in agreement with a study of Zhao et al who demonstrated that Ang II significantly prevented apoptosis in human breast cancer cells (MCF-7) and Ang II type 1 receptor was responsible for these effects (18). Moreover, the inhibitory effect of Ang II on apoptosis was also described in endothelial progenitor cells (7).

Aside from the biological assays measuring the changes in cell cycle, proliferation and apoptosis, we also analysed the expression of the main genes connected with the aforementioned processes. Three genes regulating cell cycle progression: $C C N D 1, C C N E 1$ and $M K I 67$ were analysed as markers of cell proliferation. $C C N D 1$, encoding cyclin D1 is responsible for the growth factor-induced transition from the G0 into the G1 phase (19); whereas CCNE1, whose expression occurs in the late $\mathrm{G} 1$ phase, plays a pivotal role in G1/S transition (19). Zapiecki et al showed that CCND1 expression does not correlate with the number of cells in the S+G2M phase but cyclin E expression was directly correlated with an increased population of cells in the S+G2M phase (20). Our study revealed that expression of both cyclins only in the case of well- and poorly differentiated human endometrial adenocarcinoma cells progressively increased after Ang II treatment. This tendency was also observed in the case of MKI67 mRNA expression. In terms of the role of the aforementioned genes in endometrial cancer, recently Zapiecki et al showed 
that significantly higher expression of cyclin D1 and E was detected in patients dying from endometrial cancer. Moreover, Shevra et al (21) observed increased expression of CCND1 and MKI67 in patients with endometrial carcinoma in relation to proliferative endometrium and simple hyperplasia, and they showed that CCND1 expression had a positive correlation with MKI67 expression. These findings are in agreement with our results, demonstrating that $C C N D 1, C C N E 1$ and $M K I 67$ increased in parallel with the loss of differentiation of endometrial adenocarcinoma.

The process of cancerogenesis not only changes the proliferation potential and apoptosis, but also influences the cell mobility and adhesion. Both processes are important as they contribute to cancer progression and participate in the detachment of cancer cells from the primary origin leading to metastasis $(22,23)$. EMT is closely connected with metastasis. During our research we observed increased mobility/migration and changes in adhesion potential after Ang II treatment, as well as changes in the expression of EMT-related genes: $C D H 1, T G F-\beta$, VIM, CD44, SNAI1, ZEB1 and $Z E B 2$ (data not shown). Furthermore, we previously showed that Ang II modulates EMT in prostate cancer as well as noncancerous cell lines $(9,10)$, while other research groups demonstrated this effect using other cell models (11,2427). Results from biological assays testing the mobility and adhesion processes in endometrial adenocarcinoma cells after Ang II treatment did not give us a clear answer regarding the role of angiotensin in the modulation of EMT progression, adhesion or motility. We observed an opposite response of well- vs. poorly differentiated cell lines. Gene expression analysis gave additional information on Ang II activity, which clearly depended on the differentiation status of these cancer cells. $C D H 1$ was among the analysed genes showing changes in expression after Ang II treatment. CDH1 is regarded as the main epithelial marker and loss of its expression is tightly connected with EMT. We noted that the relative expression of $C D H 1$ varied between cell lines. In the ISH cells, incubation with Ang II, administered at a dose of $10 \mu \mathrm{g} / \mathrm{ml}$, resulted in an increase in $C D H 1$ expression. The same type of response in poorly differentiated MFE-280 cells was observed after treatment with the lower dose of Ang II, whereas the higher one decreased $\mathrm{CDHI}$ expression. Similar tendencies were noted for other analysed genes tightly connected with CDH1 regulation and acquisition of mesenchymal phenotype Ang II treatment caused downregulation of $T G F-\beta$ expression in ISH cells, but in the MFE-280 cell line Ang II increased the expression of this gene. $T G F-\beta$ has a dual role in the process of cancer formation. In the early stages of neoplastic transformation it plays a suppressive role; however in later stages of cancer progression it becomes a tumour promoter. TGF- $\beta$ has been shown to regulate cell proliferation, angiogenesis, metastasis, and is an inducer of EMT $(28,29)$. It has been demonstrated that TGF $\beta 1$ synthesis can be induced by Ang II, while blockade of the RAS results in a decrease in TGF $\beta 1$-induced production of matrix proteins (30). In our endometrial cancer model this dual modulation of TGF- $\beta$ by Ang II was confirmed in both biological assays, as well as analysis of expression of EMT-related genes. In the case of the ISH cells, even though there was an increase in cell mobility and adhesion to particular ECM proteins, this cell line did not express the genes characteristic of the mesenchymal phenotype. All tested EMT markers were downregulated with accompanied increase of $\mathrm{CDH} 1$ expression. This observation could explain the increased adhesion, as the cells were more epithelial than mesenchymal in phenotype and behaviour. In contrast, the poorly differentiated endometrial cancer cell line MFE-280 after angiotensin treatment acquired a mesenchymal phenotype, which was characterized by induced expression of EMT-related genes, including VIM, CD44, SNAII, ZEB1 and $Z E B 2$ (data not shown). Changes in expression of these genes coincided with increased mobility and decreased adhesion of MFE-280 cells treated with Ang II. The decreased adhesion was quite surprising, but it may have resulted from acquisition of a strong mesenchymal phenotype, in which cells detaching from the basal membrane do not undergo cell death but survive these stressful conditions. Ang II-induced EMT observed in our study was also described by other research groups $(6,30)$. Shan et al recently showed that Ang II promotes activation of endometrial epithelium cells and significantly decreases the expression of E-cadherin, increasing the expression of SMA (6). Furthermore, Ang II together with TGF- $\beta 1$ was shown to play a central role in initiating EMT in in vitro models of metastatic tumour development (6). This interaction between Ang II and TGF- $\beta 1$ in the progression of EMT was also confirmed in other in vitro and in vivo models (31-33).

Our study demonstrated that only in poorly differentiated endometrial cancer cells was the expression of $T G F-\beta 1$ directly associated with Ang II treatment in a dose-dependent manner. Moreover, upregulation of $T G F-\beta 1$ mRNA was connected with increased SNAII expression. On the other hand, we showed that there is a connection between the basal level of cell proliferation and TGF- $\beta$ mRNA expression. Loss of TGF- $\beta$-induced growth inhibition has been associated with disruption and/or dysregulation of the TGF- $\beta$ signalling pathway, which may facilitate invasion, metastasis, and angiogenesis (29). In conclusion, our study revealed that Ang II influences endometrial cancer cells in terms of cancer-related processes, i.e., increased proliferation, reduction of apoptosis, increased mobility and modulation in adhesion potential. However, its effect and effectiveness seems to be highly associated with the differentiation status of the cancer cells. Ang II appears to play a crucial role in the early and late stages of malignant transformation.

\section{Acknowledgements}

This study was supported by the National Science Centre grant no. UMO-2013/09/B/NZ4/01365.

\section{References}

1. Wojciechowska U and Didkowska J: Illness and deaths from malignant tumors in Poland. National Cancer Registry, Cancer Centre - Institute for them. Maria Sklodowska - Curie ISSN 0867-8251. http://onkologia.org.pl/wp-content/uploads/ BIUL2013.pdf

2. Piastowska-Ciesielska AW, Płuciennik E, Wójcik-Krowiranda K, Bieńkiewicz A, Bednarek A and Ochędalski T: Analysis of the expression of angiotensin II type 1 receptor and VEGF in endometrial adenocarcinoma with different clinicopathological characteristics. Tumour Biol 33: 767-774, 2012.

3. Matysiak ZE, Ochędalski T and Piastowska-Ciesielska AW: The evaluation of involvement of angiotensin II, its receptors, and androgen receptor in endometrial cancer. Gynecol Endocrinol 31: $1-6,2015$ 
4. Rodrigues-Ferreira S, Abdelkarim M, Dillenburg-Pilla P, Luissint AC, di-Tommaso A, Deshayes F, Pontes CL, Molina A, Cagnard N, Letourneur F, et al: Angiotensin II facilitates breast cancer cell migration and metastasis. PLoS One 7: e35667, 2012.

5. Deshayes F and Nahmias C: Angiotensin receptors: A new role in cancer? Trends Endocrinol Metab 16: 293-299, 2005.

6. Shan T, Zhang L, Zhao C, Chen W, Zhang Y and Li G: Angiotensin-(1-7) and angiotensin II induce the transdifferentiation of human endometrial epithelial cells in vitro. Mol Med Rep 9: 2180-2186, 2014.

7. Yin T, Ma X, Zhao L, Cheng K and Wang H: Angiotensin II promotes NO production, inhibits apoptosis and enhances adhesion potential of bone marrow-derived endothelial progenitor cells. Cell Res 18: 792-799, 2008.

8. Tokinaga Y, Kimoto Y, Ogawa K, Mizumoto K, Tange K and Hatano Y: Reduction of adhesion formation by an angiotensin type 1 receptor antagonist. Langenbecks Arch Surg 396: 127-132, 2011.

9. Domińska K, Piastowska-Ciesielska AW, LachowiczOchędalska A and Ochędalski T: Similarities and differences between effects of angiotensin III and angiotensin II on human prostate cancer cell migration and proliferation. Peptides 37 : 200-206, 2012.

10. Piastowska-Ciesielska AW, Domińska K, Nowakowska M, Gajewska M, Gajos-Michniewicz A and Ochędalski T: Angiotensin modulates human mammary epithelial cell motility. J Renin Angiotensin Aldosterone Syst 15: 419-429, 2014.

11. Zhao Y, Wang H, Li X, Cao M, Lu H, Meng Q, Pang H, Li H, Nadolny C, Dong X, et al: Ang II-AT1R increases cell migration through PI3K/AKT and NF- $\mathrm{KB}$ pathways in breast cancer. J Cell Physiol 229: 1855-1862, 2014.

12. Zhao Y, Chen X, Cai L, Yang Y, Sui G and Fu S: Angiotensin II/angiotensin II type I receptor (AT1R) signaling promotes MCF-7 breast cancer cells survival via PI3-kinase/Akt pathway. J Cell Physiol 225: 168-173, 2010.

13. Uemura H, Ishiguro H, Nakaigawa N, Nagashima Y, Miyoshi Y, Fujinami K, Sakaguchi A and Kubota Y: Angiotensin II receptor blocker shows antiproliferative activity in prostate cancer cells: A possibility of tyrosine kinase inhibitor of growth factor. Mol Cancer Ther 2: 1139-1147, 2003.

14. De Paepe B, Verstraeten VM, De Potter CR and Bullock GR Increased angiotensin II type-2 receptor density in hyperplasia DCIS and invasive carcinoma of the breast is paralleled with increased iNOS expression. Histochem Cell Biol 117: 13-19, 2002.

15. Guo R, Gu J, Zhang Z, Wang Y and Gu C: MicroRNA-410 functions as a tumor suppressor by targeting angiotensin II type 1 receptor in pancreatic cancer. IUBMB Life 67: 42-53, 2015.

16. Kinoshita J, Fushida S, Harada S, Yagi Y, Fujita H, Kinami S, Ninomiya I, Fujimura T, Kayahara M, Yashiro M, et al: Local angiotensin II-generation in human gastric cancer: Correlation with tumor progression through the activation of ERK1/2, NF- $\mathrm{BB}$ and survivin. Int J Oncol 34: 1573-1582, 2009

17. Mohammad RM, Muqbil I, Lowe L, Yedjou C, Hsu HY, Lin LT, Siegelin MD, Fimognari C, Kumar NB, Dou QP, et al: Broad targeting of resistance to apoptosis in cancer. Semin Cancer Biol 35 (Suppl): S78-S103, 2015.

18. Zhao Y, Chen X, Cai L, Yang Y, Sui G and Wu J: Angiotensin II suppresses adriamycin-induced apoptosis through activation of phosphatidylinositol 3-kinase/Akt signaling in human breast cancer cells. Acta Biochim Biophys Sin (Shanghai) 40: 304-310, 2008.
19. Wolf G and Wenzel UO: Angiotensin II and cell cycle regulation. Hypertension 43: 693-698, 2004.

20. Zapiecki K, Manahan KJ, Miller GA and Geisler JP: Cyclin E is overexpressed by clear cell carcinomas of the endometrium and is a prognostic indicator of survival. Eur J Gynaecol Oncol 36: 114-116, 2015.

21. Shevra CR, Ghosh A and Kumar M: Cyclin D1 and Ki-67 expression in normal, hyperplastic and neoplastic endometrium. J Postgrad Med 61: 15-20, 2015.

22. Okegawa T, Pong RC, Li Y and Hsieh JT: The role of cell adhesion molecule in cancer progression and its application in cancer therapy. Acta Biochim Pol 51: 445-457, 2004.

23. Hanahan D and Weinberg RA: Hallmarks of cancer: The next generation. Cell 144: 646-674, 2011.

24. Takeda H, Katagata Y, Hozumi Y and Kondo S: Effects of angiotensin II receptor signaling during skin wound healing. Am J Pathol 165: 1653-1662, 2004.

25. Sakai H, Matsuura K, Tanaka Y, Honda T, Nishida T and Inui M: Signaling mechanism underlying the promotion of keratinocyte migration by angiotensin II. Mol Pharmacol 87: 277-285, 2015.

26. Liu Y, Tian X, Cui M and Zhao S: Safflower yellow inhibits angiotensin II-induced adventitial fibroblast proliferation and migration. J Pharmacol Sci 126: 107-114, 2014.

27. Puddefoot JR, Udeozo UK, Barker S and Vinson GP: The role of angiotensin II in the regulation of breast cancer cell adhesion and invasion. Endocr Relat Cancer 13: 895-903, 2006.

28. Bokhari AA and Syed V: Inhibition of transforming growth factor- $\beta$ (TGF- $\beta$ ) signaling by Scutellaria baicalensis and Fritillaria cirrhosa extracts in endometrial cancer. J Cell Biochem 116: 1797-1805, 2015.

29. Piestrzeniewicz-Ulanska D, Brys M, Semczuk A, Rechberger T, Jakowicki JA and Krajewska WM: TGF- $\beta$ signaling is disrupted in endometrioid-type endometrial carcinomas. Gynecol Oncol 95: 173-180, 2004.

30. Saad S, Stanners SR, Yong R, Tang O and Pollock CA: Notch mediated epithelial to mesenchymal transformation is associated with increased expression of the Snail transcription factor. Int J Biochem Cell Biol 42: 1115-1122, 2010.

31. Okazaki M, Fushida S, Harada S, Tsukada T, Kinoshita J, Oyama K, Tajima H, Ninomiya I, Fujimura T and Ohta T: The angiotensin II type 1 receptor blocker candesartan suppresses proliferation and fibrosis in gastric cancer. Cancer Lett 355: 46-53, 2014.

32. Qian YR, Guo Y, Wan HY, Fan L, Feng Y, Ni L, Xiang Y and Li QY: Angiotensin-converting enzyme 2 attenuates the metastasis of non-small cell lung cancer through inhibition of epithelial-mesenchymal transition. Oncol Rep 29: 2408-2414, 2013.

33. OkamotoK, TajimaH,NakanumaS,SakaiS,MakinoI,KinoshitaJ, Hayashi $\mathrm{H}$, Nakamura $\mathrm{K}$, Oyama $\mathrm{K}$, Nakagawara $\mathrm{H}$, et al: Angiotensin II enhances epithelial-to-mesenchymal transition through the interaction between activated hepatic stellate cells and the stromal cell-derived factor-1/CXCR4 axis in intrahepatic cholangiocarcinoma. Int J Oncol 41: 573-582, 2012. 